\title{
Karacasu Fayı'nın (GB Türkiye) Göreceli Tektonik Aktivitesinin Jeomorfik İndislerle İncelenmesi
}

\author{
Investigation of the relative tectonic activity of the Karacasu Fault (SW Turkey) by \\ geomorphic indices
}

Savaş TOPAL*

Pamukkale Üniversitesi, Jeoloji Mühendisliği Bölümü, Kınıklı Yerleşkesi, 20017, Denizli

• Geliş tarihi / Received: 26.03.2018 • Düzeltilerek geliş tarihi / Received in revised form: 21.05.2018 • Kabul tarihi / Accepted: 09.06.2018

\begin{abstract}
$\ddot{O} z$
Ege genişleme sistemindeki KB gidişli havzalardan birisi olan Karacasu Havzası, Büyük Menderes Grabeni’ni eğik olarak kesmektedir. Karacasu Havzası yaklaşık 30 km uzunluğa ve $10 \mathrm{~km}$ genişliğe sahip bir yarı graben şeklinde gelişmiştir. Grabeni GB'dan sınırlayan fay, Karacasu Fayı olarak adlandırılmaktadır. Neojen öncesi temel Menderes Masifi'nin gnays ve şistlerinden oluşur. Bu metamorfik temel üzerine havza kenarları boyunca çakıltaşı ve kumtaşları, havza merkezinde ise çamurtaşları ve kireçtaşları ile temsil edilen Miyo-Pliyosen yaşlı havza dolgusu uyumsuz olarak gelir. Üstte en genç olan birim Karacasu Formasyonu'nun Kuvaterner yaşlı kaba kırıntıları yer alır. Karacasu Fayı'nın gidişi, devamlılığı ve geometrisi dikkate alınarak, Çamköy ve Yazır olmak üzere iki ayrı segmente ayrılır. KB gidişli Karacasu Fayı'nın denetlediği dağ önleri ve drenaj alanlarında dağ önü sinüslülük oranı (Smf), vadi tabanı genişliğiyüksekliği oranı (Vf), akarsu uzunluk-gradyan indisi (SL), havza asimetri faktörü (AF), hipsometrik eğri ve integral (Hi) ve drenaj havzası şekli (Bs) indisleri, $12.5 \mathrm{~m}$ çözünürlüklü sayısal yükseklik modeli (SYM) kullanılarak hesaplanmıştır. Hesaplanan bu indislerin ortalaması kullanılarak göreceli tektonik aktivite (Iat) indisi elde edilmiştir. Elde edilen Iat indisi verileri, Çamköy ve Yazır segmentlerinin KB uçlarında çok yüksek, diğer bölümlerinde ise yüksek tektonik aktivite durumuna işaret etmektedir. Segmentlerin uzunluğu ve bölgedeki eski depremler, Karacasu Fayı'nın yakın gelecekte M6 veya üzeri büyüklükte deprem üretme potansiyeline sahip olduğunu göstermektedir.
\end{abstract}

Anahtar kelimeler: Göreceli tektonik aktivite, Jeomorfik analiz, Karacasu Fayı, Tektonik jeomorfoloji

\begin{abstract}
The NW-SE trending Karacasu basin in the Aegean Extensional System cuts obliquely the Büyük Menderes graben. The Karacasu Basin was developed in the form of a half-graben with about $30 \mathrm{~km}$ long and about $10 \mathrm{~km}$ a width. This fault is called Karacasu Fault.The Pre-Neogene basement consists of schists and gneisses of the Menderes Massif. The MioPliocene basin fill are represented by the conglomerates and sandstones along the basin margins, and mudstones and limestones at the basin center. This basin fill rest unconformably on the metamorphic basement, which is represented by the conglomerates and sandstones along the basin margins and mudstones and limestones at the basin center. The youngest unit is Quaternary units consists of coarse clastics. Based on direction, continuity and geometry of the Karacasu Fault is divided into two sub-segments as Çamköy and Yazır. Mountain front sinuosity (Smf), the ratio of valley floor width to valley height (Vf), stream length-gradient index (SL), asymmetry factor (AF), hypsometric integral (Hi) basin shape indices in the drainage areas and mountain fronts were calculated using DEM (12.5 $\mathrm{m}$ resolution) to determine the relative tectonic activity of the Karacasu Basin. By using the average of these calculated indices, the relative tectonic activity (Iat) index data point to was obtained. The relative tectonic activity of the segments with the obtained Iat index is divided into two classes. Iat index suggests very high relative tectonic activities for the NW tips of the both segments, while high tectonic activities was determined for the other parts of these segments. Based on findings on this study, the length of the segments and the ancient earthquakes in the region indicate the Karacasu Fault has a potential to produce earthquakes with M6 and or higher magnitudes earthquakes in the near future.
\end{abstract}

Keywords: Relative tectonic activity, Geomorphic analysis, Karacasu Fault, Tectonic geomorphology

\footnotetext{
* Savaş TOPAL; savastopal@pau.edu.tr; Tel: (0507) 24561 28; orcid.org/0000-0001-7451-6606
} 


\section{Giriş}

GB Anadolu gibi açılmanın halen devam ettiği bölgelerde yapılacak topografya analizleri ve drenaj ağları ile ilgili çalışmalar, özellikle mevcut tektonik süreçler ve bunların faaliyetleri hakkında bilgi vermektedir. $\mathrm{Bu}$ bilgilere ulaşmak için on yıllardır devam eden çeşitli nicel çalışmalar yapılmaktadır (Bull ve McFadden, 1977; Rockwell vd., 1985; Merritts ve Vincent, 1989; Burbank, 1992; Burbank ve Anderson, 2001; Keller ve Pinter, 2002; Kirby ve Whipple, 2012; Özkaymak, 2014; Topal vd., 2016; Topal, 2018; Topal ve Özkul, 2018). Yirminci yüzyılın başından itibaren, mevcut tektonik süreçlerin kapsamını tahmin etmeye yönelik çeşitli jeomorfik indisler öne sürülmüştür. Coğrafi bilgi sistemleri tekniklerinin hızlı gelişimi ve sayısal yükseklik modeli (SYM) kalitesinde ve erişimindeki sürekli ilerleme, çeşitli ortamlarda ve ölçeklerde jeomorfik indisleri hesaplamak ve analiz etmek için güçlü ve verimli araçlar sağlamaktadır.

Jeomorfik indisler, deformasyon süreçlerine yönelik topografik tepkileri tespit edebildiklerinden aktif tektonizmayı araştırmak için yaygın olarak kullanılmaktadırlar. $\mathrm{Bu}$ çalışmada, Karacasu Fayı'nın tektonik deformasyonu hakkında bilgiler elde etmek için fayın üzerinde ve sınırlandırdığ 1 drenaj alanlarındaki morfo- metrik özellikler analiz edilmiştir. Tektonik sinyalleri ortaya çıkarmak için, litoloji ve aktif fay özellikleri yanı sıra, ana nehirlerin uzunlamasına profillerinden jeomorfik indisler kullanılmıştır. Bu çalışma sırasında elde edilen bulgular, benzer tektonik yapıya sahip aktif fayların tanımlanması için bir gösterge olarak kullanılabilir.

Karacasu havzasının paleocoğrafyası, paleoklimatolojisi, sedimantolojisi ve tektonosedimanter evrimi hakkında çok sayıda çalışma bulunmaktadır (Açıkalın, 2005; Alçiçek ve Jimenez-Moreno, 2013; Ocakoğlu vd., 2014). Ancak bu havzanın paleosismolojisi ve havzayı batıdan sinırlayan Karacasu Fayı'nın tektonik aktivitesi hakkında henüz yapılmış bir çalışma bulunmamaktadır. $\mathrm{Bu}$ araştırma ile Karacasu Fayı'nın sinırlandırdığı drenaj alanları ve da önleri boyunca jeomorfik indisler kullanılarak, çalışma alanının göreceli tektonik aktivitesinin tahmin edilmesi amaçlanmaktadır.

\section{2. Çalışma Alanının Jeolojisi}

Ege genişleme sisteminde yer alan Karacasu havzası, KB-GD gidişlidir ve Büyük Menderes grabenini verev bir şekilde keser. Batısı normal faylarla sinırlı Karacasu Havzası yarı graben şeklinde gelişmiş, yaklaşık $30 \mathrm{~km}$ uzunluğa ve 10 $\mathrm{km}$ genişliğe sahip bir havzadır (Şekil 1).

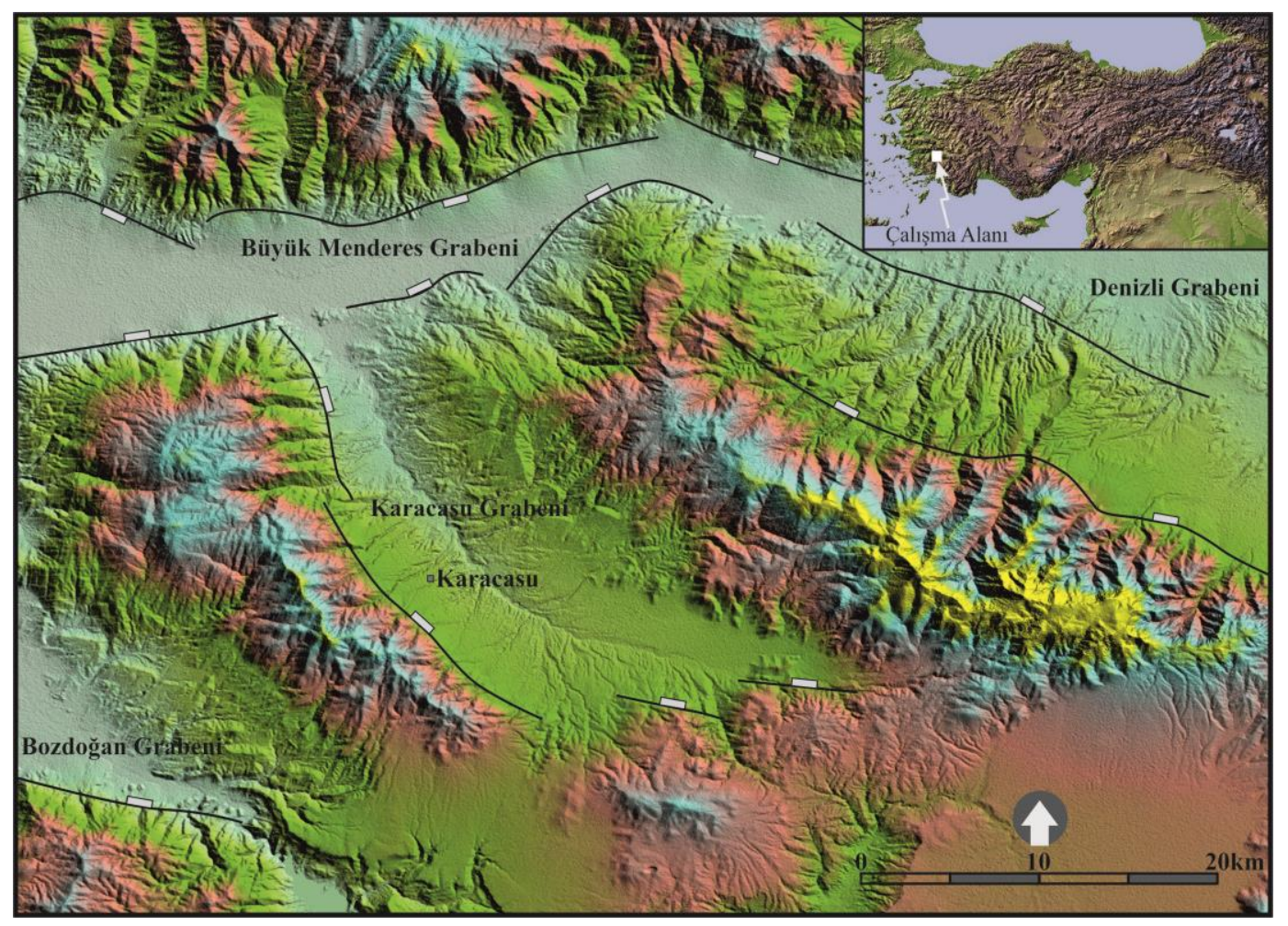

Şekil 1. Çalışma alanının yer bulduru haritası ve komşu grabenlerle ilişkisi. 
Karacasu Havzası'ndaki taban kayaları, Menderes masifini oluşturan çekirdek ve örtü metamorfitleri ile bunları tektonik olarak örten ofiyolitlerden meydana gelmektedir. Metamorfik temel, birbirlerine yanal ve düşey geçişler gösteren gnays, şist, kuvarsit ve mermerler ile birlikte, çalışma alanının güneyinde ve doğusunda metasedimanter kayaçlardan oluşur (Şimşek ve Y1lmaz, 1977). Gnayslar genellikle iki mikalı ve bazı kesimlerde gözlü gnays olarak tanımlanmaktadır (Nebert, 1955; Kastelli, 1971). Çalışma alanında en yaygın olarak görülen kaya grubu şistlerdir. Yer yer granat içerdikleri de gözlenen bu şistler, çoğunlukla mikaşist karakterindedir. Diğer bir metamorfik kayaç grubu olan kuvarsitler ise gnays ve şistler kadar yaygın olmayıp, mikaşistler ve gnayslar içinde ara bantlar halinde görülürler (Kastelli, 1971; Şimşek ve Yılmaz, 1977). Mikaşistler arasında yaygın olarak bulunan ve çoğunlukla mika içeren mermerler bazı yerlerde kalkşist görünümündedir (Kastelli, 1971). Karacasu Grabeni'nin güneydoğu kenarında ve doğu ucunda Neojen birimlerine temel oluşturan kayaçlar genellikle metasediment karakterindedir (Açıkalın, 2005, Ocakoğlu vd., 2014). Konak ve Göktaş (2004) tarafindan hazırlanan 1/100000 ölçekli jeoloji haritasında Erken Triyas'dan Geç Kretase'ye kadar değişen yaşlara sahip zayıf metamorfik çört, çörtlü kireçtaş1, çakıltaş1, kumtaşı, kireçtaşı ve dolomitlerin yayılımları gösterilmektedir. Çalışma alanında sınırlı bir yayılıma sahip olan ofiyolitik kayaçlar, oldukça altere ve bazı kesimleri neredeyse tamamen serpantinleşmiş ultramafitlerden oluşmaktadır (Açıkalın, 2005). Karbonat yoğun seviyelere de sahip olan bu kaya topluluğu, Konak ve Göktaş (2004) tarafindan Kretase yaşlı peridotitler olarak haritalanmıştır.

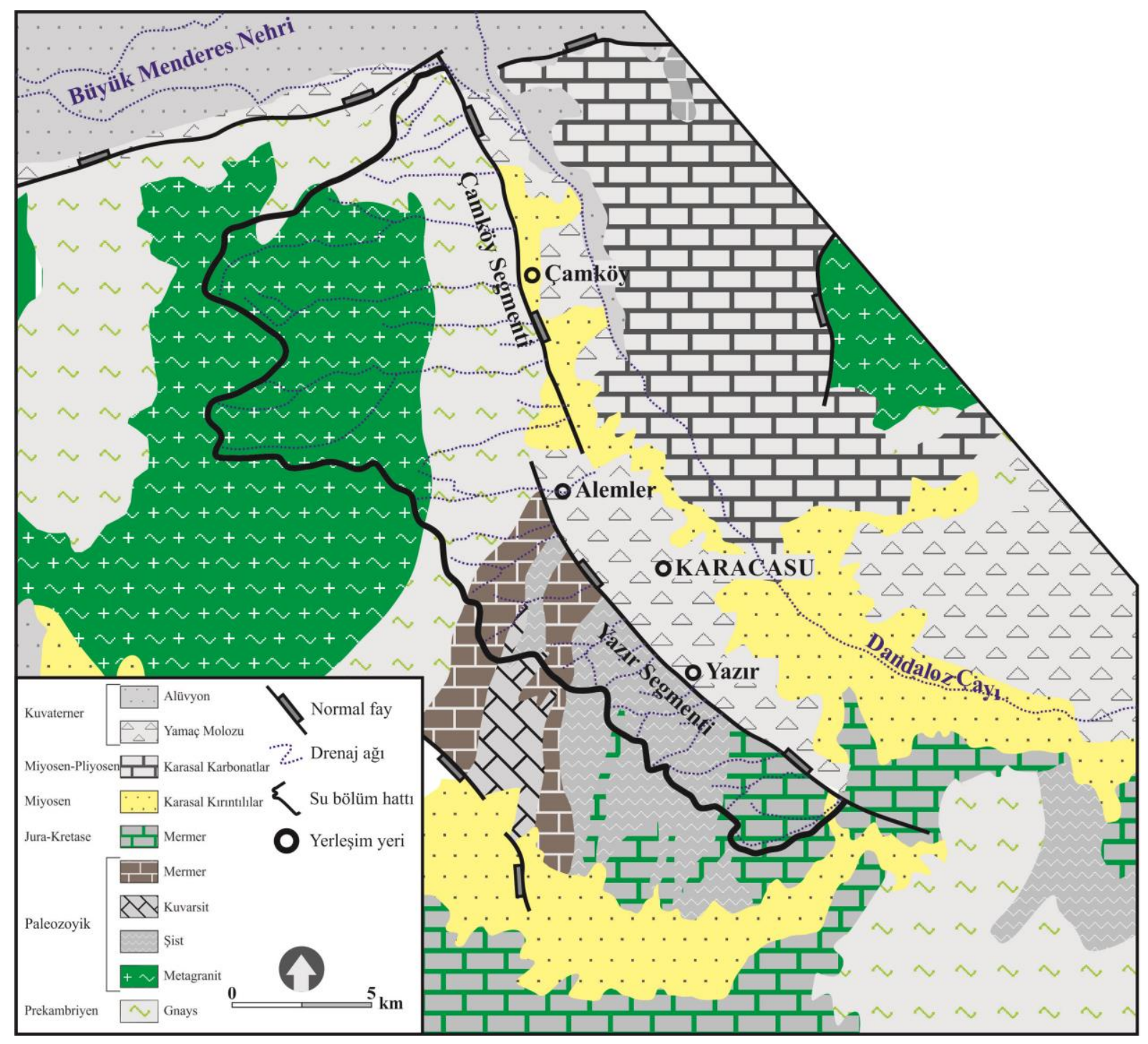

Şekil 2. Karacasu havzasının jeoloji haritası (Konak ve Göktaş, 2004; Açıkalın, 2005; Alçiçek ve JimenezMoreno, 2013; Ocakoğlu vd., 2014). 
Yaklaşık 30 km uzunluğa sahip Karacasu Fayı, KB'da Büyük Menderes Grabeninden başlayarak Alemler Köyü'ne kadar $\mathrm{K} 20^{\circ} \mathrm{B}$ doğrultusunda devam etmektedir. Alemler Köyü yakınlarında batıya doğru $500 \mathrm{~m}$ sıçrama yapan fay, buradan itibaren GD'ya doğru $\mathrm{K} 40^{\circ} \mathrm{B}$ doğrultusunda devam eder. $\mathrm{Bu}$ sıçrama nedeniyle fay 2 farklı segment şeklinde geliş̧miştir. $\mathrm{Bu}$ çalışmada, Alemler Köyü'nün kuzeyinde kalan segment Çamköy segmenti, güneyinde kalan segment ise Yazır segmenti olarak ele alınmaktadır. Çamköy segmentinin uzunluğu yaklaşık $12 \mathrm{~km}$, Yazır segmentinin uzunluğu ise yaklaşı $18 \mathrm{~km}$ 'dir. Jeomorfik indis hesaplamalarında Çamköy segmentinin sinırladığ 7 adet ve Yazır segmentinin sinırladığı 10 adet drenaj alanı kullanılmıştır.

\section{Metod}

Jeomorfik indisler, aktif bir yapı boyunca farklı yapısal bölümlerin belirlenmesinde ve potansiyel olarak en aktif segmentin tahmin edilmesinde yardımcı olabilir (Azor vd., 2002). Aktif tektonik çalışmalarında en yararlı jeomorfik indisler; dağ önü sinüslülük oran1 (Smf), vadi tabanı genişliğiyüksekliği oranı (Vf), Akarsu uzunluk-gradyan indisi (SL), havza asimetri faktörü (AF), hipsometrik eğri ve integral (Hi) ve drenaj havzas1 şekli (Bs) olarak önceki çalışmalarda olduğu gibi bu çalışmada da kullanılmıştır. Hesaplanan bu indislerin sonuçlarından göreceli tektonik aktivite indisi (Iat) elde edilmiştir. Karacasu Fayı boyunca, SYM kullanılarak 17 adet drenaj alanı oluşturulmuştur. Oluşturulan drenaj alanlarında jeomorfik indis uygulamaları sonucu elde edilen bulgular aşağıda verilmektedir.

\subsection{Dağ Önü Sinüslülük Oranı (Smf)}

Dağ önü sinüslülük oranı, önceki çalışmalarda tektonik olarak aktif dağ önlerini, yaşları dikkate alınarak aktif olmayan dağ önlerinden ayırmak için kullanılmaktadır (Bull ve McFadden, 1977; Keller ve Pinter, 2002).

$\mathrm{Smf}=\mathrm{Lmf} / \mathrm{Ls}$

Bull (1977) tarafindan önerilen formülde: dağ önünün düz çizgi uzunluğu Ls, dağın eteği boyunca dağ önü uzunluğu ise Lmf'dir. (Keller ve Pinter, 2002). Aktif faylar tarafindan sinırlanan dağ önleri düşük Smf değerleri gösterirken (Smf $<1.4)$, yüksek $\mathrm{Smf}$ değerleri $(\mathrm{Smf}>3.0)$ tektonik olmayan dağ önlerini işaret eder ve burada aşınma daha baskındır (Keller ve Pinter, 2002; Silva vd., 2003; Bull, 2007; Pérez-Peña vd., 2010).

\subsection{Vadi Tabanı Genişliği-Yüksekliği Oranı (Vf)}

Yükselmenin tektonik etkisini anlamakta kullanılan önemli indislerden birisi Vf'dir. Vf indisi ile bir drenaj alanının şekli belirlenebilir (Bull ve McFadden, 1977; Keller ve Pinter, 2002).

Vf indisi aşağıdaki formülle ifade edilir;

$\mathrm{Vf}=2 \mathrm{Vfw} /($ Eld-Esc $)+($ Erd-Esc $)$

Formülde, Vfw, vadi tabanının genişliği, Erd ve Eld, vadinin sağ ve sol kenarının yüksekliği ve Esc vadi tabanının ortalama yüksekliğidir (Bull, 1977; Bull ve McFadden, 1977).

Vf değerlerinin yüksek veya düşük olması tamamen vadinin şekline bağlıdır. "V" şekilli bir vadinin Vf değeri düşük, yükselme oranı yüksektir. (Bull ve McFadden, 1977; Rockwell vd., 1985; Silva vd., 2003; El Hamdouni vd., 2008). $\mathrm{Bu}$ makaledeki Vf değerleri, dağ önlerinden $350 \mathrm{~m}$ vadi yukarı kesimlerde hesaplanmıştır.

\subsection{Akarsu Uzunluk-Gradyan İndisi (SL)}

Vadi kanalı boyunca olası tektonik aktivite, kaya direnci ve topoğrafya arasındaki ilişkilerin değerlendirilmesi amaciyla SL indeksi kullanılmaktadır (Hack, 1973; Keller ve Pinter, 2002).

Akarsu uzunluk-gradyan indisi değeri;

$\mathrm{SL}=(\Delta \mathrm{H} / \Delta \mathrm{L}) \quad \mathrm{L}$

formülü kullanılarak hesaplanır. Bu formüle göre,

$\Delta \mathrm{H}:$ Akarsu kanalının yükseklik değişimini (maksimum yükseklik / minimum yükseklik),

\section{$\Delta \mathrm{L}$ : Akarsu segmentinin uzunluğunu,}

L: indis hesaplama noktasından, vadinin en yüksek noktasına kadar olan mesafenin metre olarak değerini ifade etmektedir (Hack, 1973; Keller ve Pinter, 2002).

Akarsu uzunluk-gradyan indisi akarsuyun akış gücüyle ilişkili olup, zirve noktasında nehrin ulaşabildiği güç önemli bir hidrolojik değişkendir ve doğrudan yatağını aşındırması ve sediman taşıması özelliklerini belirler. $\mathrm{Bu}$ indis kanal 
eğiminin değişimine çok duyarlıdır. Kanal eğimi ise olası tektonik etkinlik, kayaçların dayanımı ve topoğrafya ile ilişkilidir. SL indisi sert kayaların üzerinden geçerken artar. Buna karşılık, seylsilttaşı-bazı kumtaşları ve karbonat kayaçlardan geçerken düşer. Düşük SL değerine sahip kayaçların içinden geçerken aniden yüksek SL değerlerine sahip bir bölgenin varlığını yakalamak olası bir fayı işaret edebilir. Ayrıca çok düşük değerlerde (özellikle çizgisel bir hat boyunca) benzer şekilde yorumlanabilir.

\subsection{Havza Asimetri Faktörü (AF)}

AF'nin hesaplanması, topgrafyanın eğimini (tiltlenme miktarını) belirlemek için niceliksel olarak hızlı bir yöntemdir (Hare ve Gardner, 1985, Cox, 1994, Keller ve Pinter, 2002). Havza asimetri faktörü, drenaj alanındaki akışın hangi kenara yakın olduğunu belirleyerek, topoğrafyanın tiltlendiği yönü tespit etmek için geliştirilmiştir.

Havza asimetri faktörü;

$$
\mathrm{AF}=100(\mathrm{Ar} / \mathrm{At})
$$

formülü ile hesaplanır. Formülde, Ar, drenaj havzasındaki akışın sağında kalan bölgenin alanı, At ise drenaj alanının toplam alanını ifade eder. 50'ye yakın AF değerleri, eğilmenin az veya hiç olmadığını gösterirken, daha yüksek veya daha düşük değerler, aktif tektoniğin neden olduğu havzalardaki tiltlenmeyi gösterir.

\subsection{Hipsometrik Ĕgri ve İntegral (Hi)}

Hipsometrik eğri ve integral bir drenaj havzasının evrimi hakkında bilgi verir. Strahler (1952), hipsometrik eğrinin şekillerine dayanılarak, drenaj alanlarının diseksiyonunun (aşınım) tipik aşamalarını, (i) genç evre, (ii) olgun evre ve (iii) eski evre olmak üzere üç tip olarak sınıflandırmıştır. Konkav şekilli eğriler, havzanın genç evresiyle ilişkilidir ve bu da bölgenin az aşındırıldığını ve bozulmadığını gösterir. "S" şekilli eğriler, drenaj alanının orta-olgun evrede olduğunu ve orta derecede bir aşınmaya uğradığını gösterir. Konveks olan eğriler ise olgun evredeki drenaj alanlarını, bu alanların oldukça aşınmış ve bozulmuş olduğunu gösterir. Hipsometrik integral aşağıdaki formülle hesaplanır;

$\mathrm{Hi}=(\mathrm{hmean}-\mathrm{hmin}) /(\mathrm{hmax}-\mathrm{hmin})$
Hipsometrik integral, havza geometrisi, rölyef ve drenaj havzası alanına bağlıdır (Lifton ve Chase, 1992; Hurtrez vd., 1999; Chen vd., 2003). Havzaların gelişimi ve erozyonunun jeolojik evreleri hipsometrik integral ile hesaplanabilir. Hipsometrik integralin yüksek değeri, drenaj alanının nispeten daha az erozyona maruz kaldığını ve genç evrede olduğunu gösterir.

\subsection{Drenaj Havzast Şekli (Bs)}

Drenaj havzası şekli indeksi tektonik jeomorfolojide tamamlayıc1 bir metot olarak kullanılmıştır. Bs bir havzada iki uzak nokta arasındaki planimetrik ölçüdür (Ramirez-Herrera, 1998). Aşağıdaki formül ile hesaplanır:

$\mathrm{Bs}=\mathrm{Bl} / \mathrm{Bw}$

Formülde;

B1: Havzanın uzunluğu,

Bw: Havzanın genişliğidir.

Bs'nin yüksek değeri uzamış havzaları, düşük değeri ise daha dairesel havzaları ifade eder. Uzamış şekilli havzalar tektonik açıdan aktif alanları karakterize eder. Bu metot, Mojave Çölü (California) (Bull ve McFadden, 1977) ve Acambay Grabeni (Meksika) (Ramírez-Herrera, 1998) gibi tektonik açıdan aktif olduğu düşünülen dağ önlerine yakın drenaj havzalarına uygulanmıştır.

\subsection{Göreceli Tektonik Aktivite İndisi (Iat)}

Hesaplanan bütün jeomorfik indislerin ortalamas1 kullanılarak göreceli tektonik aktivite indisi oluşturulur (El Hamdouni vd., 2008). Bu indis eski çalışmalarda bir bölgenin göreceli tektonik aktivitesinin belirlenmesi için yaygın bir şekilde kullanılan en önemli indislerden birisidir. Çalışılan bölgedeki jeomorfik indislerin bir özetini ve ortalamasını temsil eder:

Iat $=\mathrm{S} / \mathrm{N}$

$\mathrm{S}$, indis sonuçlarının toplamı ve $\mathrm{N}$, seçilen indislerin sayısıdır (El Hamdouni vd., 2008). Bu indisin sonuçları, aktif tektoniğin derecesini tanımlamak amacıyla dört sınıfa ayrılmıştır: 1 -çok yüksek $(1.0 \leq$ Iat $<1.5)$; 2-yüksek $(1.5 \leq$ Iat $<2.0)$; 3 - orta (2.0 $\leq$ Iat $<2.5)$; ve 4 düşük $(2.5 \leq$ Iat $)$ (El Hamdouni vd., 2008). 


\section{Jeomorfik İndis Sonuçları ve Tartışma}

Jeomorfik indis sonuçlarını tartışmadan önce indislerin hesaplandığı kayaç türlerinin aşınmaya karşı dayanımlarını araştırmakta fayda vardır. Drenaj alanlarının üzerinde geliştiği kayaç türlerinin aşınıma karşı direnci, hesaplanan indislerde değişimlere yol açmaktadır. Selby (1980) tarafından tanımlanmış kaya direnci sınıflandırması kullanılarak inceleme alanındaki litolojilerin dayanıklılığı tespit edilmiştir. Buna göre kayaçlar; düşük dayanımlı (alüvyon, yamaç molozu), orta dayanımlı (karasal kırıntılılar ve karasal karbonatlar) ve yüksek dayanımlı (metagranit, kuvarsit, gnays, şist ve mermerler) olmak üzere üç kategoriye ayrılmıştır. Karacasu fayının sınırladığı drenaj alanlarının tamamı Menderes masifine ait kayaçlar üzerinde gelişmiştir (Şekil 2). Menderes masifine ait aşınıma dayanıklı kayaçlar (metagranit, kuvarsit, gnays, şist ve mermerler) üzerinde gelişen bu drenaj alanlarında tektonik yükselme genellikle aşınımdan daha baskındır (Şekil 2).

$\mathrm{Bu}$ çalışmada SYM kullanılarak elde edilen jeomorfik indis sonuçları, Karacasu Fayı'nı oluşturan segmentlere göre aşağıda verilmektedir (Şekil 6) (Tablo 1).

\section{1. Çamköy Segmenti}

Karacasu havzasını batıdan sınırlandıran Karacasu Fayı boyunca uzanan dağ önleri için Smf değerleri hesaplanmıştır (Şekil 6) (Tablo 1). Çamköy segmenti için 1.52 ile 2.51 arasında değişen bu değerler ortalaması 1.91 olarak elde edilmiştir. Smf indisi önceki çalışmalarda göreceli tektonik aktiviteye göre (sınıf 1: $\operatorname{Smf}>1.1$; sinıf 2: $1.1 \leq$ Smf $<1.5$ ve sınıf 3: Smf $\geq 1.5$ ) 3 sınıfa ayrılmıştır (El Hamdouni vd., 2008). Çamköy segmentinin 1.5 'ten büyük Smf değerleri, göreceli tektonik aktivite bakımından 3. sınıfa dahil olduğunu göstermektedir. Smf değerinin 3. Sinıf tektonik aktiviteye karşılık gelmesi fay önünde gelişen yamaç molozları ve alüvyal yelpazelerin dağ önündeki düzlüğü bozmasıyla açıklanabilir. Çamköy segmentinin sınırladığı drenaj alanlarında hesaplanan Vf değerleri $0.21-0.65$ arasında değişmektedir. Ortalaması ise 0.43 olarak hesaplanmıştır. El Hamdouni vd. (2008), tarafından yapılan çalışmada Vf indisi değerlerine göre drenaj alanları göreceli tektonik aktivite açısından 3 farklı sınıfa (sınıf $1: \mathrm{Vf} \leq 0.5 ; \sin ı f 2$ $(0.5 \leq \mathrm{Vf}<1.0$ ve sinıf $3: \mathrm{Vf} \geq 1)$ ayrılmıştır. $\mathrm{Bu}$ sinıflamaya göre Vf indisinin ortalama değeri göreceli tektonik aktivitenin 1. sınıfına karşılık gelmektedir. Önceki çalışmalarda Smf ve Vf indisleri beraber analiz edilmiş ve bu iki indisin analizi, hem o bölgedeki tektonik aktivitenin belirlenmesine, hem de yükselme oranının belirlenmesi hakkında bilgi vermektedir (Rockwell vd., 1984). Smf ve Vf indislerinin analizi sonucunda Çamköy segmentinin göreceli tektonik aktivitesi orta sınıf olarak belirlenmiştir. Yükselme oranı da $0.05-0.5 \mathrm{~mm} / \mathrm{y} 1 \mathrm{l}$ olarak hesaplanmıştır (Şekil 3).

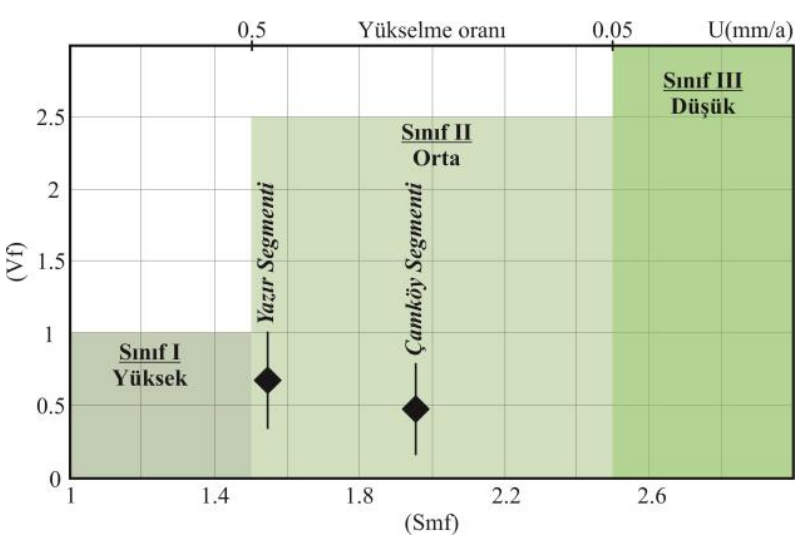

Şekil 3. Karacasu Fayı'nı oluşturan dağ önlerinde hesaplanan dağ önü sinüslülük oranı (Smf) ve vadi tabanı genişliği-yüksekliği oranı (Vf) değerlerinin grafiği ve Rockwell vd., (1984) tarafından ileri sürülen yükselme oranları.

Çamköy segmentinin sınırladığı drenaj alanlarında, her $200 \mathrm{~m}$ yükseklik boyunca SL indisi hesaplanmıştır (Şekil 4 ve 6). Hesaplanan SL indisinin en düşük değeri 100 (2 nolu drenaj alanı), en yüksek değeri de 460 (6 nolu drenaj alanı) olarak elde edilmiştir (Şekil 4) (Tablo 1). Önceki çalışmalarda SL indisi 3 farklı tektonik sinifa (sinif 1: $S L \geq 120$; $\sin 1 f$ 2: $80 \geq \mathrm{SL} \leq 119$ ve sınıf 3: SL $\leq 79$ ) ayrılmıştır (El Hamdouni vd., 2008). Çamköy segmenti için ortalama SL indis değeri 198 olup, göreceli tektonik aktivite 1. sınıf olarak belirlenmiştir.

Çamköy segmentinin sınırladığı drenaj alanlarında AF indisi hesaplanmıştır. Hesaplanan indis değerlerinin en düşüğü 4 nolu $(\mathrm{AF}=45)$ ve en yüksek değeri de 7 nolu $(\mathrm{AF}=74)$ drenaj alanında hesaplanmıştır (Tablo 1). AF'nin 50'den büyük olduğu drenaj alanları KB'ya doğru tiltlenmeyi gösterirken, 50'den düşük AF değerleri GD'ya doğru eğime işaret etmektedir (Şekil 6) (Tablo 1). El Hamdouni vd. (2008), tarafindan yapilan çalışmada AF indisi 3 farklı tektonik sınıfa ayrılmıştır. Bu sınıflamaya göre: 1. sınıf: $A F>65$ veya $A F<35$; 2 . sinif: $36<A F>43$ veya $57<A F>65$; 3. sınif: $44<\mathrm{AF}>57$ şeklindedir. Hesaplanan $\mathrm{AF}$ indis değerleri (45-74), Çamköy segmentinin 1. derecede tektonik aktiviteye sahip olduğunu öngörmektedir (Tablo 1). 


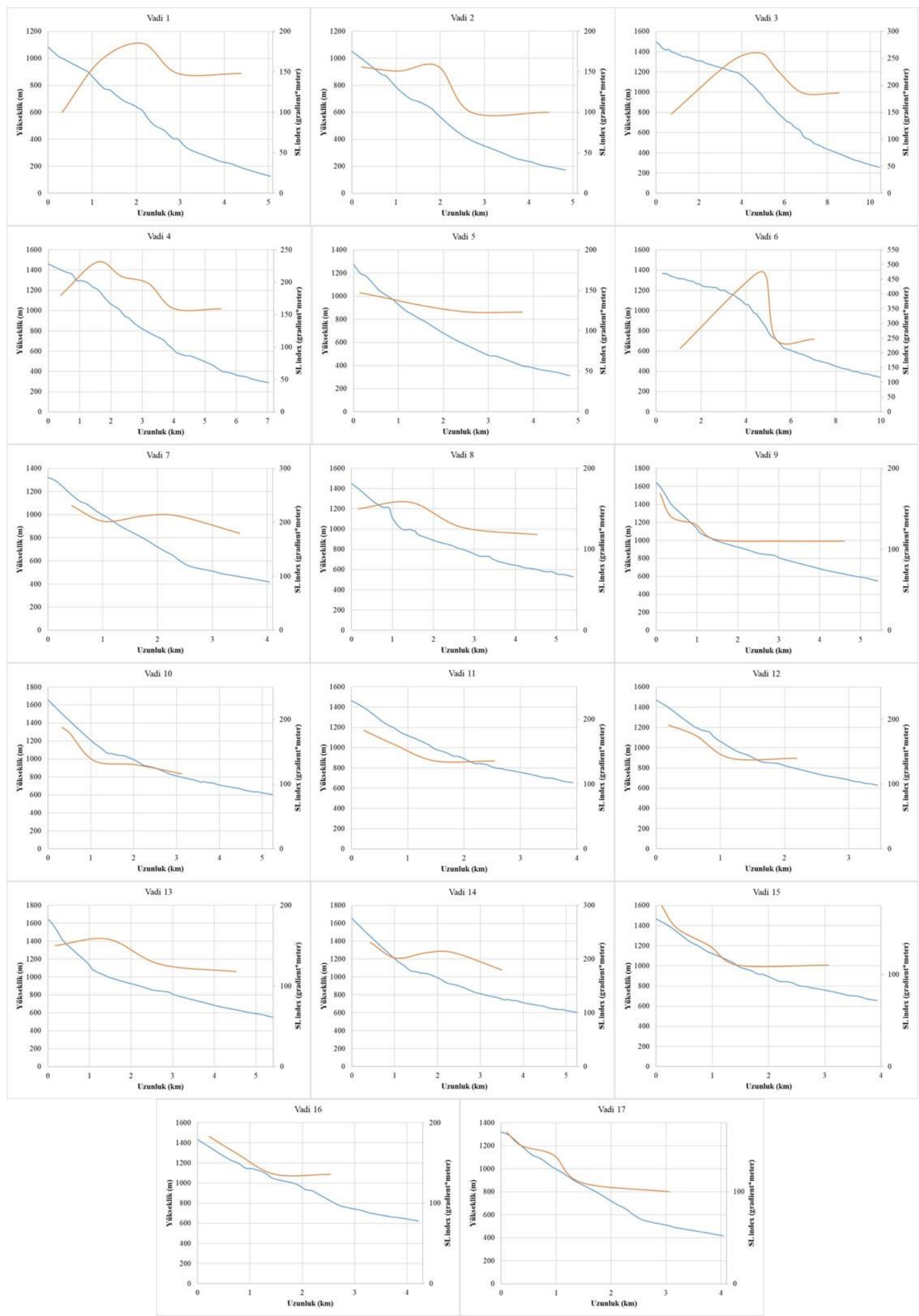

Şekil 4. İnceleme alanındaki 17 adet drenaj alanı için boyuna nehir profilleri ve ölçülen SL değerleri.

Çamköy segmentinin sınırladığı drenaj alanları (17 nolu drenaj alanları) boyunca hesaplanan hipsometrik integral (Hi) değerleri 0.36-0.57 arasında değişmektedir (Tablo 1). En düşük Hi değeri 2 nolu, en yüksek değer ise 4 nolu drenaj alanında hesaplanmıştır. Elde edilen hipsometrik eğrilerin görünümlerine bakıldığında, drenaj alanlarının orta-genç evre safhasında olduğu 
anlaşılmaktadır. $\mathrm{Bu}$ eğrilerin genellikle $\mathrm{S}$ şekilli veya dış bükey olduğu, özellikle 6 nolu drenaj alanında elde edilen dış bükey profilden bu drenaj alanının net olarak genç evreyi işaret ettiği anlaşılmaktadır (Şekil 5). Hi değerlerinin tektonik sinıflamasi: 1. sinıf: $\mathrm{Hi}>5 ; 2$. sinıf: $5>\mathrm{Hi}>4 ; 3$. sınıf: $\mathrm{Hi}<4$ şeklindedir (El Hamdouni vd., 2008). Bu sinıflamaya göre 4 ve 7 nolu drenaj alanları 1 . sinif, 1, 3, 5 ve 6 nolu drenaj alanları 2. sinif ve 2 nolu drenaj alanı da 3. sinif tektonik aktiviteye karşı11k gelmektedir.

Drenaj havzası şekli (Bs) indisi hesaplamalarından elde edilen değerler 3.25-7.92 arasında değişmektedir (Tablo 1). Bs'nin en düşük değeri 6 nolu, en yüksek değeri ise 1 nolu alanda hesaplanmıştır. Elde edilen bu değerler, Çamköy segmentinin sinırladığı bu drenaj alanlarının uzamış havzalar olduğunu, başka bir deyişle tektonizmadan oldukça etkilendiğini göstermektedir. Bs değerlerinin göreceli tektonik aktivitesi eski çalışmalara göre 3 sınıfa ayrılmıştır. El Hamdouni vd. (2008)'in yaptı̆̆ siniflama: 1 . sinıf: (Bs $\geq 4) ; 2$. sinıf $(3 \leq \mathrm{Bs} \geq 4)$ ve 3 . sinıf (Bs $\leq 3)$ şeklindedir. $\mathrm{Bu}$ sinıflamaya göre Çamköy segmentinin sinırladığı drenaj alanlarından 6 nolu alan 2. sinıf, diğerleri ise 1. sinıf tektonik aktiviteye karş1lık gelmektedir (Tablo 1).
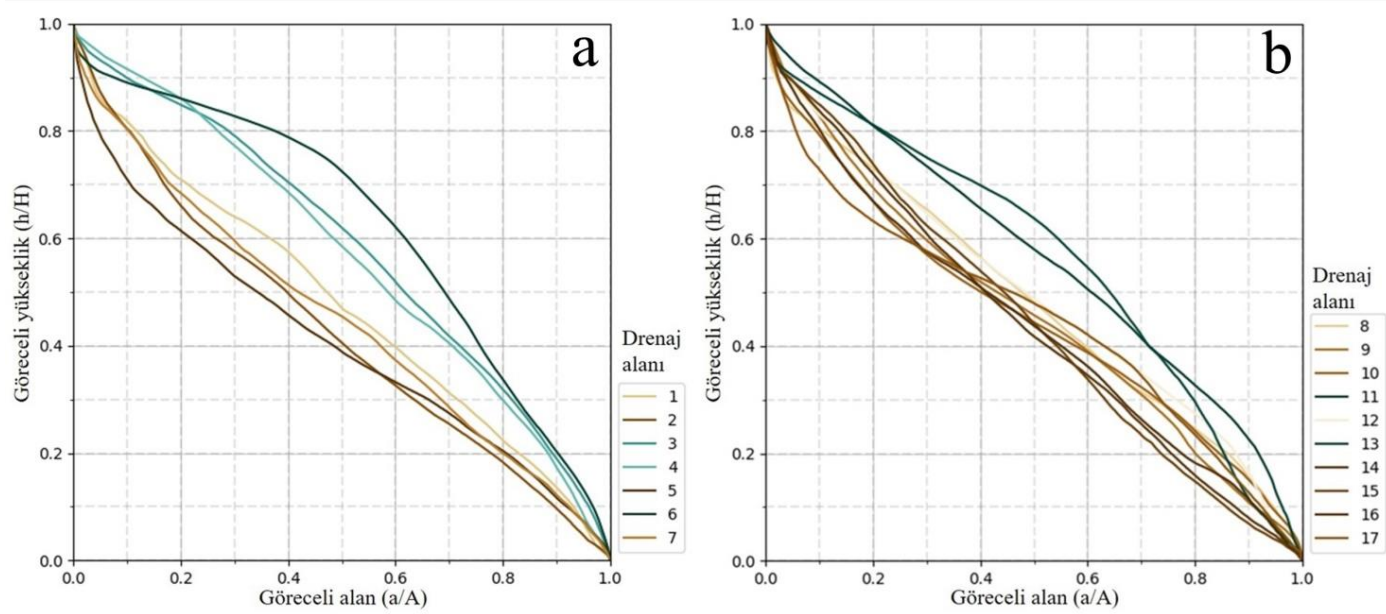

Şekil 5. (a) Çamköy segmentinin sınırladığı, (b) Yazır segmentinin sınırlanığı drenaj alanlarında elde edilen hipsometrik eğriler.

Tablo 1. Çalışma alanının göreceli tektonik aktivitesini belirlemek için kullanılan jeomorfik indis değerleri.

\begin{tabular}{|c|c|c|c|c|c|c|c|c|c|c|c|c|c|}
\hline Drenaj & Toplam & Smf & & & Vf & SL & $\mathrm{Hi}$ & $\mathrm{AF}$ & & & Bs & & \\
\hline 1 & 2.76 & \multirow{3}{*}{5.79} & \multirow{3}{*}{3.81} & \multirow{3}{*}{1.52} & 0.38 & 149 & 0.44 & 2.76 & 1.66 & 60 & 4.75 & 0.60 & 7.92 \\
\hline 2 & 4.55 & & & & 0.65 & 141 & 0.36 & 4.55 & 3.23 & 71 & 4.58 & 1.09 & 4.20 \\
\hline 3 & 15.06 & & & & 0.48 & 213 & 0.42 & 15.06 & 8.72 & 58 & 9.10 & 1.38 & 6.59 \\
\hline 4 & 9.50 & 6.65 & 3.87 & 1.72 & 0.34 & 195 & 0.57 & 9.50 & 4.25 & 45 & 6.86 & 1.55 & 4.43 \\
\hline 6 & 29.57 & \multirow{2}{*}{8.70} & \multirow{2}{*}{3.46} & \multirow{2}{*}{2.51} & 0.21 & 339 & 0.48 & 29.57 & 19.82 & 67 & 9.16 & 2.82 & 3.25 \\
\hline 7 & 3.70 & & & & 0.53 & 214 & 0.55 & 3.70 & 2.74 & 74 & 4.27 & 0.92 & 4.64 \\
\hline 8 & 6.99 & \multirow{8}{*}{23.67} & \multirow{8}{*}{15.65} & \multirow{8}{*}{1.51} & 0.69 & 138 & 0.51 & 6.99 & 3.95 & 57 & 5.09 & 1.33 & 3.83 \\
\hline 9 & 6.88 & & & & 0.82 & 141 & 0.63 & 6.88 & 2.60 & 38 & 5.15 & 1.09 & 4.72 \\
\hline 12 & 2.41 & & & & 0.94 & 123 & 0.55 & 2.41 & 1.10 & 46 & 3.18 & 0.90 & 3.53 \\
\hline 13 & 2.99 & & & & 0.37 & 138 & 0.39 & 2.99 & 1.64 & 55 & 3.57 & 0.64 & 5.58 \\
\hline 14 & 3.25 & & & & 0.47 & 214 & 0.41 & 3.25 & 1.77 & 54 & 3.50 & 0.99 & 3.54 \\
\hline 15 & 3.32 & & & & 0.61 & 135 & 0.45 & 3.32 & 1.52 & 46 & 3.54 & 0.77 & 4.60 \\
\hline 16 & 2.55 & & & & 0.81 & 160 & 0.33 & 2.55 & 1.55 & 61 & 3.12 & 1.08 & 2.89 \\
\hline 17 & 2.58 & & & & 1.07 & 141 & 0.37 & 2.58 & 1.97 & 76 & 3.26 & 0.73 & 4.47 \\
\hline
\end{tabular}




\subsection{Yazır Segmenti}

Karacasu Fayı'nı oluşturan segmentlerden birisi olan Yazır segmenti boyunca uzanan dağ önleri için Smf değeri 1.51 olarak hesaplanmıştır (Şekil 6) (Tablo 1). El Hamdouni vd. (2008), tarafindan yapılan sinıflamaya göre Yazır segmentinin göreceli tektonik aktivitesi 3. sinıf olarak belirlenmiştir. Yazır segmentinin sınırladığı drenaj alanlarında hesaplanan Vf değerleri 0.371.07 arasında değişmektedir. Hesaplanan Vf değerlerinin ortalamas 0.69 'dur. El Hamdouni vd. (2008), tarafindan yapılan sinıflamaya göre Vf indisinin ortalama değeri göreceli tektonik aktivitenin 1. sınıfına karşılık gelmektedir. Smf ve
Vf indislerinin birlikte analizi sonucunda Yazır segmentinin göreceli tektonik aktivitesi orta sinıftır. Yükselme oranı da $0.05-0.5 \mathrm{~mm} / \mathrm{y} 1 \mathrm{l}$ olarak hesaplanmıştır (Rockwell vd., 1984) (Şekil 3).

Yazır segmentinin sınırladığ 10 adet drenaj alanında $200 \mathrm{~m}$ yükseklik aralığında hesaplanan SL indisinin en düşük değeri 123 (12 nolu drenaj alanı), en yüksek değeri de 214 (14 nolu drenaj alanı) olarak elde edilmiștir (Şekil 4 ve 6) (Tablo 1). Yazır segmenti için SL'nin ortalama değeri 150 olup, önceki çalışmalarda SL indisi için yapılan sinıflamaya göre göreceli tektonik aktivitesi 1. sınıf olarak belirlenmiştir (El Hamdouni vd., 2008).

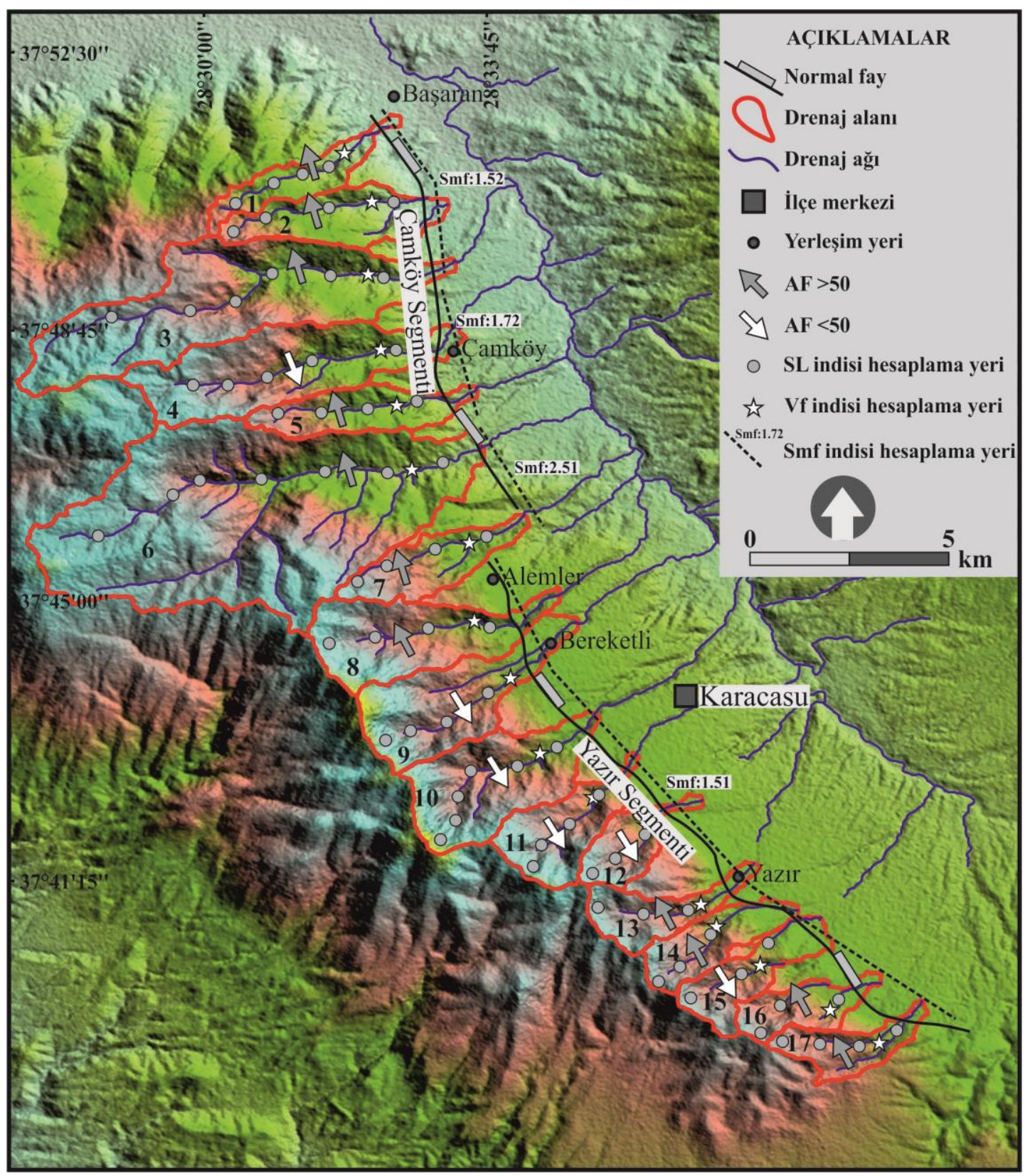

Şekil 6. Karacasu Fayı'nı oluşturan segmentlerin sınırladığı drenaj alanlarında ve dağ önleri boyunca hesaplanan jeomorfik indislerin yerleri. 
Yazır segmentinin sinırladığı 10 adet drenaj alanında AF indisi hesaplanmıştır. En düşük $\mathrm{AF}$ değeri 9 nolu $(\mathrm{AF}=38)$ ve en yüksek $\mathrm{AF}$ değeri de 17 nolu $(\mathrm{AF}=76)$ drenaj alanında hesaplanmıştır (Tablo 1). 50'den yüksek $\mathrm{AF}$ değeri drenaj alanlarında KB'ya doğru olan tiltlenmeyi, 50'den düşük $\mathrm{AF}$ değerleri de GD'ya doğru olan vadi eğimini göstermektedir (Şekil 6) (Tablo 1). El Hamdouni vd. (2008), tarafindan yapilan siniflamaya göre AF indis değerleri, Yazır segmentinin 1. derecede tektonik aktiviteye sahip olduğunu göstermektedir (Tablo 1).

Yazır segmentinin sınırladığı drenaj alanlarında (8-17 nolu drenaj alanları) hesaplanan Hi değerleri 0.33-0.63 arasında değişmektedir (Tablo 1). En düşük Hi değeri 16 nolu, en yüksek değer ise 17 nolu alandan elde edilmiştir. $\mathrm{Bu}$ değerlerden çizilen hipsometrik eğrilerin görünümlerine bakıldığında, drenaj alanlarının orta-genç evrede olduğu ve eğrilerin genellikle $\mathrm{S}$ şekilli veya dış bükey olduğu belirlenmiştir (Şekil 5). El Hamdouni vd. (2008), tarafindan yapılan sinıflamaya aktarıldığında, 8, 9, 12 nolu drenaj alanları 1. sinif, 10, 11, 14, 15 nolu alanlar 2. sinif ve 16,17 nolu drenaj alanları da 3. sinıf tektonik aktiviteye karşıllk gelmektedir.

Yazır segmenti boyunca 10 adet drenaj alanında Bs indisi hesaplanmıştır. Hesaplamalardan elde edilen değerler 2.85-5.58 arsinda değişmektedir. Bs'nin en düşük değeri 10 nolu, en yüksek değeri ise 13 nolu drenaj alanından elde edilmiştir (Tablo 1). $\mathrm{Bu}$ değerler, Yazır segmentinin sinırladığ drenaj alanlarının uzamış havzalar olduğunu ve tektonizmadan oldukça etkilendiğini ortaya koymaktadır. El Hamdouni vd. (2008)'in yaptığ1 sınıflamaya göre Yazır segmentinin sinırladığ 1 drenaj alanlarından 9, 13, 15, 17 nolu alan 1. sinif, $8,11,12,142$. sinif ve 10,16 nolu alanlar da 3. sınıf tektonik aktiviteye karşılık gelmektedir (Tablo 1).

Iat indisi değerlerine göre yapılan sınıflamada;

- Çok yüksek göreceli tektonik aktivite: 1,8 ve 9 nolu drenaj alanlarında,

- Yüksek göreceli tektonik aktivite: 2, 3, 4, 5, 6, $7,11,12,13,14,15,17$ nolu drenaj alanlarında

- Orta göreceli tektonik aktivite: 10 ve 16 nolu drenaj alanlarında belirlenmiştir.

Iat indis değerleri dikkate alındığında, Çamköy ve Yazır segmentlerinin KB uçları çok yüksek göreceli tektonik aktiviteyi gösterse de fayın geneline bakıldığında, Karacasu Fayı yüksek göreceli tektonik aktiviteye sahip olduğu söylenebilir.

\section{Sonuçlar}

Sayısal yükseklik modeli kullanılarak yapılan morfometrik çalışmalar, bir bölgenin göreceli tektonik aktivitesini belirlemede kullanılabilir. Karacasu Fayı'nın göreceli tektonik aktivitesini belirlemek amacıyla yapılan bu çalışmada, dağ önleri için; dağ önü sinüslülük oranı (Smf), vadi tabanı genişliği-yüksekliği oranı (Vf), fayın sınırladığ 1 drenaj alanları için; akarsu uzunlukgradyan indisi (SL), havza asimetri faktörü (AF), hipsometrik eğri ve integral (Hi) ve drenaj havzası şekli (Bs) indisleri kullanılmıştır. Hesaplanan jeomorfik indisler için, eski çalışmalar kullanılarak üç farklı tektonik sınıf belirlenmiştir. $\mathrm{Bu}$ tektonik sinıflandırmaların ortalaması alınarak her bir drenaj alanı için göreceli tektonik aktivite indisi Iat hesaplanmıştır. Iat indisine göre, Çamköy ve Yazır segmentlerinin KB uçları çok yüksek derecede göreceli tektonik aktiviteye sahiptir. Segmentlerin diğer bölümlerinde hesaplanan Iat değerleri de yüksek derecede tektonik aktiviteyi işaret etmektedir. Elde edilen veriler, segmentlerin uzunluğu ve bölgede meydana gelen eski depremler dikkate alındığında, Karacasu Fayı'nın M6 veya üstü büyüklüğe sahip deprem üretme potansiyeline sahip olduğu sonucuna varılmıştır.

\section{Kaynaklar}

Açıkalın, S., 2005. Sedimentary evolution of the Karacasu cross-graben (Aydın, West Anatolia). MSc, Eskişehir Osmangazi University, Eskişehir, Turkey.

Alçiçek, H. ve Jiménez-Moreno, G., 2013. Late Miocene to Pliocene fluvio-lacustrine system in Karacasu Basin (SW Anatolia, Turkey): depositional, palaeogeographic and palaeoclimatic implications. Sedimentary Geology, 291, 62-83.

Azor, A., Keller, E.A. ve Yeats, R.S., 2002. Geomorphic indicators of active fold growth; South Mountain-Oak Ridge Anticline, Ventura Basin, Southern California. Geological Society of America Bulletin, 114, 745-753.

Bull, B. W., 1977. Tectonic geomorphology of the Mojave Desert, U.S. Geological Survey Contact Report 14-08-001-G-394. 
Bull, W.B. ve McFadden, L.D., 1977. Tectonic geomorphology North and south of the Garlock fault, California, Proceedings of the Eighth Annual Geomorphology Symposium, in: Geomorphology in Arid Regions, Doehring, D. O., (Ed), State University of New York, Binghamton, 115138.

Burbank, D.W. ve Anderson, R.S., 2001. Tectonic Geomorphology. Blackwell Science.

Burbank, D.W., 1992. Causes of recent Himalayan uplift deduced from deposited patterns in the Ganges basin. Nature, 357, 680-683.

Chen, Y.C., Sung, Q. ve Cheng, K.Y., 2003. Along-strike variations of morphotectonic features in the Western Foothills of Taiwan: Tectonic implications based on streamgradient and hypsometric analysis. Geomorphology, 56, 109-137.

Cox, R.T., 1994. Analysis of Drainage-Basin Symmetry as a Rapid Technique to Identify Areas of Possible Quaternary Tilt-Block Tectonics An Example from the Mississippi Embayment. Geological Society American Bulletin, 106, 571-581.

El Hamdouni, R., Irigaray, C., Fernández, T., Chacón, J. ve Keller, E.A., 2008. Assessment of relatiand actiand tectonics, southwest border of the Sierra Nevada (southern Spain). Geomorphology, 96.

Hack, J.T., 1973. Stream profile analysis and stream gradient index. Journal of Research of the United States Geological Survey, 1 (4), 421-429.

Hare, P.W. ve Gardner, T.W., 1985. Geomorphic indicators of vertical neotectonism along converging plate margins, Nicoya Peninsula, Costa Rica, Proceedings of the $15^{\text {th }}$ Annual Binghamton Geomorphology Symposium, in: Tectonic Geomorphology, Morisawa, M. and Hack, J.T., (Eds), Allen and Unwin, Boston, 123-134.

Hurtrez, J.E., Lucazeau, F., Lavé, J. ve Avouac, J.P., 1999. Investigation of the relationships between basin morphology, tectonic uplift, and denudation from the study of an active fold belt in the Siwalik Hills, central Nepal.
Journal of Geophysical Research, 104, 12779-12796.

Kastelli, M., 1971. Denizli-Sarayköy-ÇubukdağKaracasu alanı jeoloji incelemesi, MTA Raporu, Derleme No: 2532.

Keller, E.A. ve Pinter, N., 2002. Active tectonics: Earthquakes, Uplift, and Landscape $\left(2^{\text {nd }}\right.$ Edn.): New Jersey, Prentice Hall, 432 p.

Kirby, E. ve Whipple, K.X., 2012. Expression of Active Tectonics in Erosional Landscapes. Journal of Structural Geology, 44, 54-75.

Konak, N. ve Göktaş, F., 2004. 1/100.000 ölçekli Türkiye jeoloji haritalanı serisi, DenizliM21 paftas1: MTA Gen. Müd. Jeoloji Etütleri Dairesi, Ankara.

Lifton, N.A. Ve Chase, C.G., 1992. Tectonic, climatic and lithologic influences on landscape fractal dimension and hypsometry: implications for landscape evolution in the San Gabriel Mountains, California. Geomorphology, 5, 77-114.

Merritts, D. ve Vincent, K.R., 1989. Geomorphic response of coastal streams to low, intermediate, and high rates of uplift, Medocino triple junction region, northern California. Geological Society of America Bulletin, 101(11) 1373-1388.

Nebert, K., 1955. Bozdoğan ve Karacasu'daki genç Neojen körfezleri, MTA Raporu, Derleme No. 2511.

Ocakoğlu, F., Açıkalın, S., Özsayin, E. ve Dirik, K., 2014. Tectonosedimentary evolution of the Karacasu and Bozdoğan basins in the Central Menderes Massif, W Anatolia. Turkish Journal of Earth Sciences, 23(4), 361-385.

Özkaymak, Ç. ve Sözbilir, H., 2012. Tectonic geomorphology of the Spildağ high ranges, western Anatolia. Geomorphology, 173174, 128-140.

Pérez-Peña, J.V., Azor, A., Azañón, J.M. ve Keller, E.A., 2010. Actiand tectonics in the Sierra Nevada (Betic Cordillera, SE Spain): Insights from geomorphic indexes and drainage pattern analysis. Geomorphology, $119,74-87$. 
Ramírez-Herrera, M.T., $1998 . \quad$ Geomorphic assessment of active tectonics in the Acambay graben, Mexican Volcanic Belt. Earth Surface Processes and Landforms, 23, 317-332.

Rockwell, T.K., Keller, E.A., ve Jonson, D.L., 1985. Tectonic geomorphology of alluvial fans and mountain fronts near Ventura, California, Proceedings of the $15^{\text {th }}$ Annual Geomorphology Symposium, in: Tectonic Geomorphology, Morisawa, M. (Ed), Allen and Unwin Publishers, Boston, 183-207.

Selby, M.J., 1980. A rock mass strength classification for geomorphic purposes: with test from Antarctica and New Zealand . Zeitschrift für Geomorphologie, 24, 31-51.

Silva, P.G., Goy, J.L., Zazo, C. ve Bardajm, T., 2003. Fault generated mountain fronts in Southeast Spain: geomorphologic assessment of tectonic and earthquake activity. Geomorphology, 250, 203-226.
Strahler, A.N., 1952. Hypsometric (area-altitude) analysis of erosional topography. Bulletin of the Geological Society of America, 63, 1117-1142.

Şimşek, Ş. ve Yılmaz, S., 1977. Nazilli-KuyucakYenice (Karacasu) alanının jeolojisi ve jeotermel olanakları, MTA Raporu, Derleme No: 6422.

Topal, S. ve Özkul, M., 2018. Jeomorfik İndisler Kullanılarak Honaz Fayı'nın (GB Türkiye) Göreceli Tektonik Aktivitesinin Belirlenmesi. Pamukkale Üniversitesi Mühendislik Bilimleri Dergisi. PAJES18199, doi: 10.5505/pajes.2017.18199.

Topal, S., 2018. Quantitative analysis of relative tectonic activity in the Acıgöl fault, SW Turkey. Arabian Journal of Geosciences, 11: 198.

Topal, S., Keller, E., Bufe, A. ve Kocyiğit, A., 2016. Tectonic geomorphology of a large normal fault: Aksehir fault, SW Turkey. Geomorphology, 259, 55-69. 